\title{
Generating Academic Success through Social Networking
}

\author{
Christopher B. Carl, Océane E. Boulais, Caroline Navega Desouza, Aleksey Levkovsky, \\ Reshma S. Thomas, Wayne E. Bernard, Kevin Lopez and Daniel S. Lotarynski \\ Mentor: Maria M. Larrondo-Petrie, Ph.D. \\ Florida Atlantic University, USA \\ \{ccarl2, oboulais2013, cnavega, olevkovskyi2015, thomasr2013, wbernard, klopez2013, dlatryn, petrie\}@fau.edu
}

\begin{abstract}
By forming intimate study groups, the void of community within the intense academic lifestyle of engineering students can be filled, creating long-lasting connections throughout a student's academic career. This research paper explores and analyzes the techniques of a student-led ad-hoc study group that was formed for a core engineering course. Through examining the trends of a successful student-led study group and its evolutionary transformation enabled by social networking, techniques of developing more collaborative environments for engineering students are enhanced.

Keywords: Academic Success, Engineering Education, Social Networking
\end{abstract}

\section{INTRODUCTION}

\section{A. Importance of Collaborative Studying}

According to the American Society for Engineering Education, the key reasons that the engineering discipline has a $40-50 \%$ dropout rate in the U.S is, "...the difficulty of the engineering curriculum; and a lack of "belonging" within engineering [1]." The dawn of social media has allowed humanity to communicate with one another unlike any other time in history. Information is available at lightning speed and we are able to share it with each other equally as fast and through a vast array of social outlets (i.e. Facebook, WhatsApp, Twitter, etc.). These social media have enabled us to connect and share information with one another in every setting-from personal to business to academic. WhatsApp messenger was particularly useful in this study of how social media played a part in improving the learning experience in a college classroom setting. The authors are undergraduate students that formed an ad-hoc study group in an engineering course. Throughout this paper, they describe the formation and evolution of their study group and the results on their performance.

Group collaboration and reflection is critical to academic success for undergraduate students. Other studies have explored the effectiveness of collaborative testing environments and would even suggest them to be a more effective evaluation strategy. However, few studies have focused on testing group construction, especially when an important factor, i.e., group diversity is taken into consideration [2]. Enhancing the learning experience of engineering students should magnify the chances of long-term academic success and persistence in the engineering field.

Digital Object Identifier (DOI): http://dx.doi.org/10.18687/LACCEI2016.1.2.057 ISBN: 978-0-98228996-9-3

ISSN: $2414-6390$

\section{B. Course Description}

Approximately seventy-five students were enrolled in the Introduction to Logic Design course at Florida Atlantic University during the fall semester of 2015. This class is a core course and prerequisite for many of the required classes for computer science, computer engineering and electrical engineering students. The course consisted of four hours of lecture per week, six lab assignments to be completed in the laboratory outside of the classroom ( $25 \%$ of total grade), ten quizzes ( $45 \%$ of total grade), a final exam ( $25 \%$ of total grade), and participation grade ( $5 \%$ of total grade).

The professor did not curve, nor drop any grades, nor gave partial credit, but provided an opportunity to retake any quiz with a ten-point penalty for each subsequent attempt. In the absence of a perfect grade, each group member attempted the quizzes until a completely satisfactory and/or maximum grade was achieved.

At the beginning of the semester, a lab tutorial was held by the teaching assistants during one class session, with the intent of teaching the students how to operate the software and the hardware in the lab, so that they could successfully complete the lab assignments. The class was split into two large groups and each group rotated between a one-hour workshop on Altera Quartus simulation software and lab orientation that day. Students completed the labs during their own time and had them graded by the teaching assistants during scheduled lab monitoring times. Labs had a hard deadline by which they needed to be graded, no extensions were given.

\section{Group Evolution}

\section{Group Formation and Structure}

During the demonstration in the lab tutorial, one student decided to videotape the session to review later and shared the video by broadcasting the link to the entire class via Blackboard. However, not everyone received the link, so other methods were used with which to share the videos (i.e. Google Drive, Samsung's S-Beam and WhatsApp messenger). WhatsApp messenger proved to be the most efficient, ultimately.

During the lecture time, the professor used Think-PairShare Technique while doing exercises, so students interacted with at least four students around them in class. One of the students with whom the video was shared, began an ad-hoc group on WhatsApp with the students that sat near her in class. This is when WhatsApp Group One came to be. The intent was to provide an informal setting where students "are able to pool

14 ${ }^{\text {th }}$ LACCEI International Multi-Conference for Engineering, Education, and Technology: "Engineering Innovations for Global Sustainability”, 20-22 July 2016, San José, Costa Rica. 
information, share resources, and check [for individual] errors [3]". Group One originated with fourteen members, most of whom had administrator capacity on Whatsapp messenger, enabling them to add new members to the group as they saw fit.

\section{Group Schism}

The stages of the group development are illustrated in Figure 1. As Group One expanded quickly throughout the first thirty-two days of the semester, from September 9th to October 11th, 2016, the original members perceived that there was a direct negative correlation between the size of the group and its effectiveness as a whole. Some studies show that having more members in a group helps in decision making [4], but the quality of Group One was beginning to suffer as a result of its growth. A larger group certainly came with its challenges, namely, content control, the frequency of messages sent or received and each member's motive for being in the group. When messages are sent in a large group, because of the volume of messages, the members react in different ways. The way a group member understands the message is congruent with their beliefs. Communication can be led by "(1) life positions that result from experiences in early childhood, (2) stereotypes, (3) the status and position of the communicator, (4) previous experiences, and (5) assumptions and values. Thus, what might appear to a naive observer as a simple, straightforward and objective social interaction, might have considerable hidden meaning for both the sender and the receiver" [5]. It was also noted that individual participation of some group members declined over time and this could have been a result of varying factors. It's plausible that some people worked better alone or had formed subgroups of their own, eliminating the need to be a part of Group One.

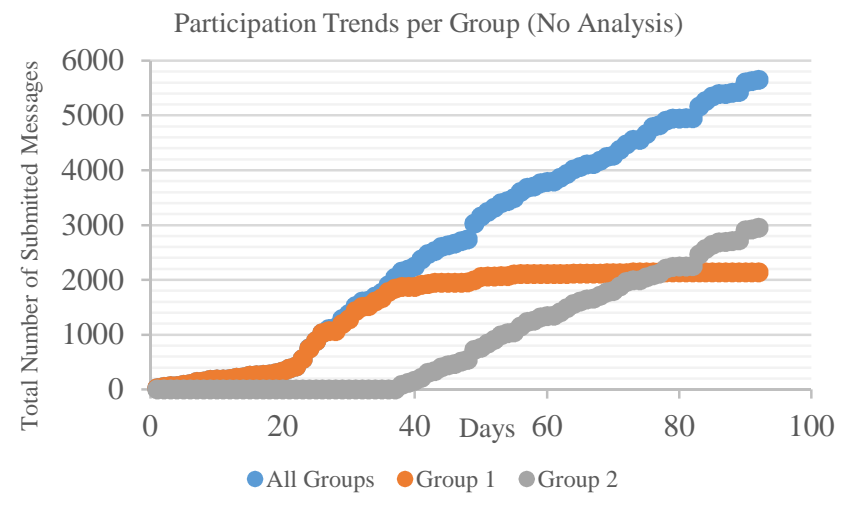

Fig. 1. Participation Trends per Group, Chronologically. Note: Group Two was a disruptor and caused Group One to experience rapid attrition.

As a result of these dynamics, there was a notable need to restructure the group. In lieu of having possibly uncomfortable conversations for reform, a second group (referred to as Group Two from here on out) was birthed with the intent of refocusing the chat to what Group One was originally created for-to provide a friendly, academic atmosphere, within which students learned from and encouraged one another. It is natural for groups to branch out into where their "emotional bonds and interests [tie] among subsets of group members. The number of participants within a group is a key factor to its growth; especially in groups when it becomes too big and cumbersome for detailed oriented assignments."[4]

Group Two originated mid-semester and at this point in time, it was easy to set apart the individuals who had joined the group to truly learn, versus those who were simply "free riding". In the Proceedings of the ACM 2009 International Conference on Supporting Group Work, the definition of free riding is described as, "individual members of a group [who] might not expend the effort since other members of the group are contributing ideas [6]." With this in mind, Group Two's members were selected in a rather objective way. Those members who demonstrated not only the will to study hard and do their part in the course, but also those who were interested in the success of their classmates, were selected to participate in Group Two. Bonding was also a factor in member selection. By this point, we had already established a solid camaraderie between the founding fathers of the original group, so Group Two essentially consisted of nine of the original members from Group One.

After the semester was finished, a survey was given to students who participated in both groups in order to determine what features of each group most engaged, or disengaged for that matter, each member. It was determined that students who persisted on to Group Two preferred the second Group One $00 \%$ more than the original because of the clear-cut goals that were established, the schedule coordination and the group size which collectively made the second chat more effective than the first. Group Two schedules overlapped making it easier to meet up in study areas such as the Cube in the Engineering East building at Florida Atlantic University. It was easier for Group Two to find study areas for nine people rather than fourteen. Group Two had "regular interaction among members and a common group identity. This means that [the group had] a sense of 'we-ness' that [enabled] members to identify themselves as belonging to a distinct entity." [8]

\section{Student Perspectives}

It is crucial to understand each student's point of view who participated in this research, as they were the constants that made this study feasible. Because of the small scale of our research control groups, we were able to obtain the specific perspectives from each student and question them on what they believe makes a study group successful, academically and professionally.

"Honestly, it [the study group] would need to consist of people whom I think are at the top of the class who want to overcome collective action problems and generally don't want to be in a group because they're loners by nature." - Chris Carl

"An attribute that I would like to see is dedication; that the people in the group care for each other and want to work hard." - Reshma Thomas

"I would participate in a group where dedication, respect, comradery and the willingness to push oneself are its biggest attributes. Coming from a business background, I can genuinely say that teamwork is indispensable when trying to achieve a common goal, particularly in an engineering setting, where so much collaboration is involved and required." - Caroline Navega Desouza 
"I would like to be included in a group where the other members have prior knowledge of the course content." - Kevin Lopez

"A group should always consist of people who are determined to succeed on whatever the group is based on. The main goal of this same group should be to progress in some way with knowledge. Lastly, the group should be filled with people who strive not only for their own success, but the whole group's." - Daniel Lotarynski

"The members of the group need to regard each other positively enough to enjoy each other's company, yet their primary goal shouldn't steer too far away from accomplishing something tangible, like sharing and absorbing knowledge together." - Aleksey Levkoskyi

"I've experienced many study groups that have attempted unified success \& have failed for a myriad of reasons, but with the group that was formed during the Introduction to Logic Design course, we have figured out the closest thing to a secret of an academically successful study group. As a student, I want to replicate this group for my other courses, however the success rate is never guaranteed. At the heart of this study group are motivated students who truly care; students who formed the group themselves with necessary self-discipline and external pressures from the class that catalyze a dynamic network of people who all aim for academic success." - Océane E. Boulais

"At the core of successful groups, I usually observe two very distinct characteristics. The first, a common goal uniting even the most unlikely of allies and the second, an occurrence out of the ordinary or unanticipated. As social beings the desire to work together, I believe, is embedded in all of us. When an unexpected situation occurs, the faux persona of protection we surround ourselves with is dropped allowing genuine connection with others. In moments such as [these] friendships are formed." - Wayne Bernard.

\section{Methodology}

This paper attempts to enumerate the qualitative and quantitative aspects of group formation, performance and conclusions to repeat the phenomenon Group Two experienced, in future groups. First, we examine the data we were originally able to gather and the techniques to parse that data into analyzable subsets of data. Secondly, we analyze this data to quantify communication frequency over time, participation within groups, grade performance on ten quizzes and six lab assignments, the group dynamic at large, and the ethnic composition of the group. Thirdly, we draw several outcomes that can be used to reproduce Group Two's phenomenon in the future like group composition recommendations, professor involvement in group formation, class format, and individual performance considerations.

\section{A. Data Gathering}

Our groups were organized using the WhatsApp messenger application - a multi-platform communication tool that allows individual users to create groups and invite people in their list of contacts to join that group. There is an option on the bottom of the "Group Info" menu called "Email Chat". This allows any user to receive a transcript of the conversation, optionally including any media, to any email address of the user's choosing.

Theoretically, a transcript of the conversations between Groups One, Two and all other groups created during the class's duration could be used to gather data such as total posts per day, post content, individual user activity, and eventually be quantified in a way that could be compared to other metrics like grade data or user satisfaction level. The raw transcript is unusable as data, other than qualitative content without analysis software like Microsoft Office's Excel, or fragmenting it into smaller chunks using customized scripts. Both Excel and custom scripts were used to extract other datasets.

\section{B. Data Manipulation}

Initially the transcript had to be parsed into a format that could be analyzed using Microsoft Office Excel. Excel uses "tab" or "It" whitespace to separate pieces of data into its cells, so the first script Transcript Parsing (see Appendix A) handles this task to produce results found in Tables I and II.

TABLE I

\begin{tabular}{|c|c|c|}
\hline \multicolumn{3}{|c|}{ Excerpt from "[Group One].txt" before parsing } \\
\hline 11/23/2015 9:26 AM & Student $H$ : & Does anyone have to retake any quizzes? \\
\hline 11/23/2015 9:26 AM & Student F: & $\mathrm{Me}$ \\
\hline 11/23/2015 9:30 AM & Student $H$ : & Which one? \\
\hline 11/23/2015 9:39 AM & Student F: & The counter one and quiz 2 \\
\hline 11/23/2015 9:51 AM & Student H: & $\begin{array}{l}\text { I have to retake the counter also...u want } \\
\text { to study together? }\end{array}$ \\
\hline 11/23/2015 9:52 AM & Student $F$ : & $\mathrm{Sii}$ \\
\hline 11/23/2015 9:57 AM & Student F: & I will be there around 12 \\
\hline 11/23/2015 10:09 AM & Student $G$ : & Is that the transition table one? \\
\hline 11/23/2015, 10:13 AM & Student H: & Yup \\
\hline $11 / 23 / 2015,10: 13 \mathrm{AM}$ & Student $G$ : & $\begin{array}{l}\text { I gotta retake that one too. I'd be up for } \\
\text { studying. }\end{array}$ \\
\hline
\end{tabular}

Using Excel, the total messages posted per day by the group and individually can be created. To create the total messages posted per day by the group, the total amount of times that a date appeared in the parsed conversation was recorded as the total number of messages for that day. The same process was applied to each individual person, such that every instance of a date translated to the total messages that day. This data was recorded as an array in Excel, cell after cell in a column. This numerical data per day could be further quantified into the total for that day or the average per day. ---Total Parsing--- and --Average Parsing--- were used to create these other sets.

TABLE 2

Excerpt from "[Group One - Parsed].txt"

\begin{tabular}{|c|c|c|}
\hline 11/25/2015 7:38 PM & Student I: & $\begin{array}{l}\text { Happy thanksgiving everyone! I just } \\
\text { want to say that when I first walked into } \\
\text { that logic class, I never for a second } \\
\text { thought I'd make any friends much less } \\
\text { join a study group. You guys kicked butt } \\
\text { this year and I am so happy to have met } \\
\text { all of you. }\end{array}$ \\
\hline 11/25/2015 8:02 PM & Student H: & $\begin{array}{l}\text { Happy thanksgiving to you too Student } \\
\text { I! I second your thoughts as well. This } \\
\text { group has been nothing short of amazing } \\
{[\ldots] \text { You're all so awesome in your own }} \\
\text { ways [...] I'm blessed to know all of you. } \\
\text { Here's to acing logic together and to the } \\
\text { many more classes and good memories } \\
\text { we'll make! Love you guys! }\end{array}$ \\
\hline
\end{tabular}

$1^{\text {th }}$ LACCEI International Multi-Conference for Engineering, Education, and Technology: "Engineering Innovations for Global Sustainability”, 20-22 July 2016, San José, Costa Rica. 
While any programming language would have sufficed, PHP was used as the language of choice because of the explode() and list() functions, which are extremely useful. The workflow of the analysis was to create a custom PHP script, save it, open the transcript or numerical array depending on the script being used, open XAMPP, begin the Apache server, open a browser, navigate to localhost/scripts/script.php, and reload the page. Two files, "input.txt" and "output.txt", which served as the data that was manipulated, were saved in the directory c:/temp. Depending on what was being manipulated in the data, the code would be commented out and the script was run as needed.

\section{DATA}

\section{A. Individual Data}

The goal of acquiring the group transcripts was to create other data sets, specifically any data that would indicate how the groups were participating or how individuals were participating within those groups. First, the number of messages per day per person were tallied in a text document. This was accomplished using Excel and manually counting the occupied cells, although this could have been accomplished with advanced scripting. Then, another custom PHP script found in Appendix A, e.g. ---Total Parsing--- was used to produce the data observed in Table III, comparing the participation of three students in Group One and Two, as an example of running the parsing algorithm.

TABLE III

Student A, H, and N Comparison of Number of Messages

\begin{tabular}{|c|c|c|c|c|c|c|}
\hline 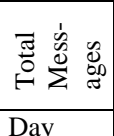 & $\begin{array}{c}\text { Student } \\
\text { A } \\
\text { Group } \\
\text { One }\end{array}$ & $\begin{array}{c}\text { Student } \\
\text { A } \\
\text { Group } \\
\text { Two }\end{array}$ & $\begin{array}{c}\text { Student } \\
\mathrm{H} \\
\text { Group } \\
\text { One }\end{array}$ & $\begin{array}{c}\text { Student } \\
\text { H } \\
\text { Group } \\
\text { Two }\end{array}$ & $\begin{array}{c}\text { Student } \\
\mathrm{N} \\
\text { Group } \\
\text { One }\end{array}$ & $\begin{array}{c}\text { Student } \\
\mathrm{N} \\
\text { Group } \\
\text { Two }\end{array}$ \\
\hline 35 & 2 & 0 & 363 & 0 & 155 & 0 \\
\hline 36 & 6 & 0 & 372 & 0 & 165 & 0 \\
\hline 37 & 6 & 0 & 378 & 0 & 175 & 0 \\
\hline 38 & 6 & 0 & 386 & 22 & 177 & 5 \\
\hline 39 & 6 & 0 & 386 & 27 & 177 & 5 \\
\hline 40 & 6 & 0 & 386 & 28 & 177 & 7 \\
\hline
\end{tabular}

\section{B. Group Dynamic Data}

As was similarly done for the individuals, the group analysis begins in the same way. First, the number of messages per day, per group were tallied in a text document. This was accomplished using Excel and manually counting the occupied cells, although this could have been accomplished with advanced scripting. Then, another custom PHP script found in Appendix A, e.g. ---Average Parsing--- produced the data observed in Table IV, comparing the total and average number of messages.

TABLE IV

Group One vs Group Two Average Messages

\begin{tabular}{|c|c|c|c|c|c|c|}
\hline Day & 岁 & 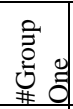 & $\begin{array}{ll}0 \\
0 \\
0\end{array}$ & 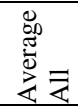 & 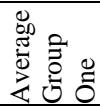 & 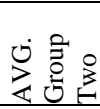 \\
\hline $10 / 13 / 2015$ & 63 & 63 & 0 & 50.34 & 47.63 & 0 \\
\hline $10 / 14 / 2015$ & 112 & 112 & 0 & 52.92 & 49.42 & 0 \\
\hline $10 / 15 / 2015$ & 62 & 62 & 0 & 55.14 & 49.76 & 0 \\
\hline $10 / 16 / 2015$ & 113 & 28 & 85 & 56.66 & 49.18 & 85 \\
\hline $10 / 17 / 2015$ & 36 & 0 & 36 & 56.13 & 47.92 & 60.5 \\
\hline $10 / 18 / 2015$ & 58 & 0 & 40 & 56.18 & 46.73 & 53.67 \\
\hline
\end{tabular}

\section{Grades}

The grades for Introduction to Logic Design were largely at, or above, a B+. Although Table $\mathrm{V}$ would seem to indicate a more standardized grade curve for the whole class, the reality is that the grades skewed with a left tail. For this publication, we've omitted most of the assignments to save space, but it should be noted that there were a total of ten quizzes, six lab grades and one final exam.

TABLE V

Example of Quiz Grades and Lab Grades

\begin{tabular}{|c|c|c|c|c|c|c|c|c|c|}
\hline$\underset{\tilde{D}}{\stackrel{\overrightarrow{0}}{0}}$ & $\stackrel{-N}{\Xi}$ & 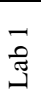 & $\begin{array}{l}+ \\
\stackrel{N}{\Xi}\end{array}$ & 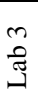 & $\begin{array}{l}\stackrel{0}{*} \\
\stackrel{ }{\Xi}\end{array}$ & 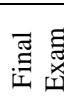 & 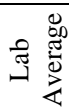 & 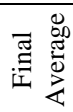 & 茎急 \\
\hline 1 & 94 & 12 & 80 & 13 & 80 & 89 & 93 & 90 & A- \\
\hline 2 & 100 & 12 & 60 & 14 & 90 & 84 & 76 & 78 & $\mathrm{C}+$ \\
\hline 11 & 100 & 12 & 65 & 0 & 50 & 61 & 81 & 68 & $\mathrm{D}+$ \\
\hline 36 & 100 & 12 & 100 & 0 & 0 & 40 & 14 & 32 & $\mathrm{~F}$ \\
\hline 37 & 79 & 12 & 100 & 15 & 100 & 92 & 96 & 94 & A \\
\hline 65 & 96 & 12 & 70 & 15 & 100 & 85 & 95 & 85 & B \\
\hline 68 & 91 & 12 & 80 & 15 & 45 & 92 & 99 & 89 & $\mathrm{~B}+$ \\
\hline $\mathrm{N}$ & 91 & 12 & 63 & 15 & 65 & 83 & 100 & 87 & $\mathrm{~B}$ \\
\hline $\mathrm{L}$ & 100 & 12 & 85 & 15 & 60 & 86 & 100 & 90 & A- \\
\hline $\mathrm{I}$ & 100 & 12 & 90 & 15 & 70 & 81 & 100 & 87 & B \\
\hline $\mathrm{H}$ & 91 & 12 & 75 & 15 & 65 & 86 & 100 & 90 & A- \\
\hline
\end{tabular}

\section{Qualitative Analysis}

We can attribute the success of Group Two to many varying factors, some of which are quantitative, but many of which are qualitative in nature. Some of these factors included the mutual will to succeed in the course, the alignment of our schedules, a positive blend of personalities and socializing together outside of the academic setting.

Our goal to understand the course material and do well in the class was a unanimous one and also a large part of what kept us going as a group. Almost all of our schedules aligned perfectly, which facilitated this objective. It allowed us to not only coordinate study sessions, but social outings as well. Our study sessions generally took place a few hours before class or immediately afterward, but academic gatherings certainly were not limited to this. We spent several hours in the lab working on our bi-weekly project assignments, making ourselves available to help not only those members within Group Two, but other classmates as well.

Academics aside, social gatherings were a necessary buffer. Whether these outings were formal dinners, quick lunch dates or a coffee break, they very much contributed to how we bonded and got to know each other on a personal level. Our bonding outside of class solidified friendships between different members of the group based on common interests; collaborations on outside projects developed; birthdays were endearingly commemorated and the list goes on. There is no doubt that the geniality that exists within this group is cohesive.

It is notable that Group Two was significantly diverse. The myriad of differences--cultural, philosophical, moral, basic likes and dislikes, and even gender--all contributed to an incredible array of personalities that meshed so seamlessly with one another. Given these differences, we have all questioned whether our group would have been successful (in terms of

14 ${ }^{\text {th }}$ LACCEI International Multi-Conference for Engineering, Education, and Technology: "Engineering Innovations for Global Sustainability", 20-22 July 2016, San José, Costa Rica. 
friendship) in any other setting and the mutual consensus is that it would have been improbable.

\section{ANALYSIS}

\section{A. Individual Trends}

\section{Individual Participation}

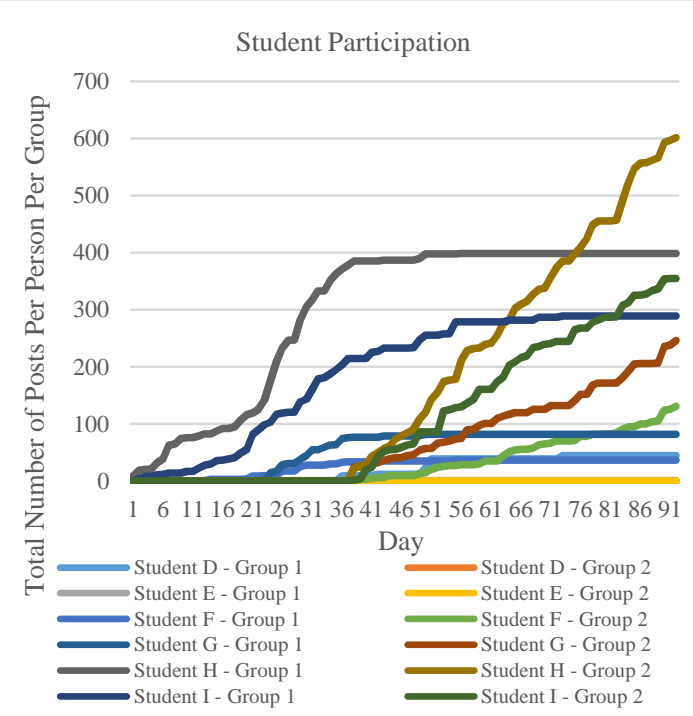

Fig. 2. Total Posts in Groups One and Two per Student regardless of presence in group. Note: Students in Group One had inconsistent behavior, all students in Group Two had consistent behavior.

Generally speaking, the first established group experienced attrition and did not sustain itself neither as a group — evident in Figure 1-nor on an individual basis-evident in Figure 2. Most importantly, the behavior of Group One was non-linear. It was perfectly linear for the first twenty-one days, then experienced a shock of activity. This created the perception of being overly saturated, leading to the schism into Group Two on day thirty-eight. Day thirty-eight caused Group One to experience a logarithmic rate of activity instead of the linear activity it showed promise.

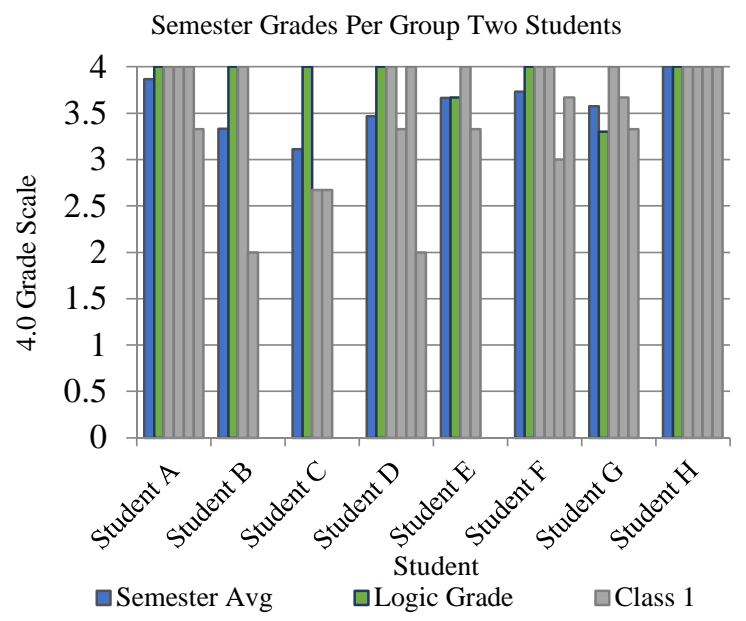

Fig. 3. Logic Design Grade vs. Student Semester Performance. Note: Students in Group Two scored the best in the Introduction to Logic Design class where Group Two was active.
Furthermore, it should be noted that all groups were taken into account and are represented in the "All Groups" lines. These represent both WhatsApp groups. It should be noted further that "All Groups" as a whole actually experienced linear behavior. However, it experienced a greater rate of linear behavior than Group Two. This analysis is sound because the other groups were exclusive groups.

\section{Individual Semester Grades}

Based on the accumulation of the group's semester grades, there was often a stark contrast between each group member's grades in the Intro to Logic Design class versus the grades they received in other courses. As seen in Figure 3, this was already a group of high-achieving students who demonstrated academic success in their semester averages, but the grades received in the Introductory Logic Design Course are generally the highest per individual. This figure serves as a strong visual representation as to how impactful the study group was for the specified course versus the other courses taken by each student.

\section{B. Group Trends}

\section{Participation Graph}

Creation of Group Two causes Group One to experience attrition immediately. Group One had inconsistent participation and its participation became logarithmic whereas Group Two had constant, linear participation. Note that Group Two also experienced linear behavior, and continued to climb at the same rate throughout its recorded lifespan. These trends are visualized in Figure 1.

\section{Accurate Trend Lines}

Trend lines were applied to the relevant portions of the graphs for Figure 4. Day twenty-one marked a spike in activity in Group One and all groups. Days 1-21 experienced none-tolittle activity. Group One was originally linear, causing the log comparison to be less appropriate. By taking days 1-21 out of the data set for Group One, the correlation became exactly logarithmic. Overall, Group Two exhibited lower slope than all the groups combined.

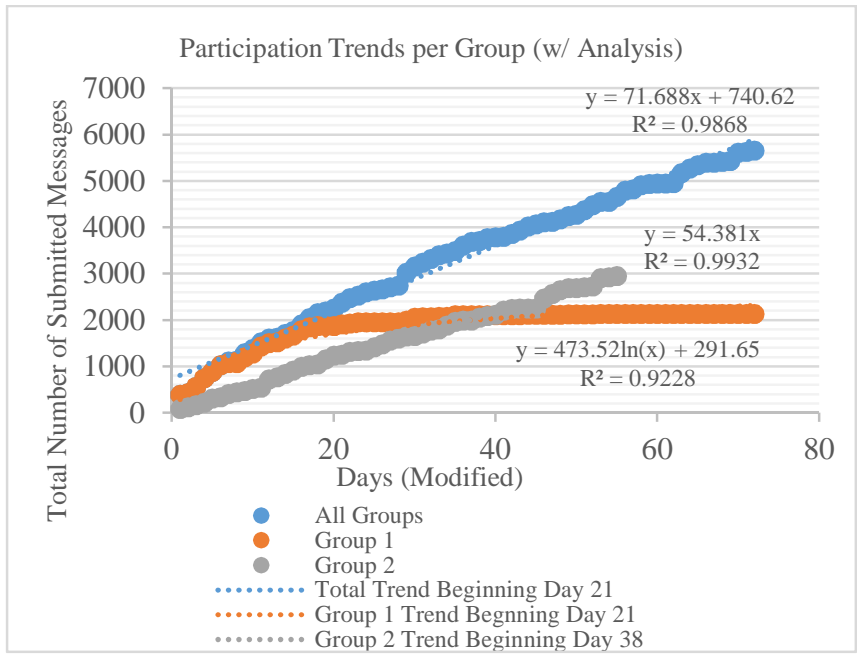

Fig. 4. Group Two exhibited a linear rate of growth while Group One exhibited a logarithmic rate.

14 ${ }^{\text {th }}$ LACCEI International Multi-Conference for Engineering, Education, and Technology: "Engineering Innovations for 


\section{Daily Average Group Participation Graph}

Each group's participation was also evaluated per week. As the groups progressed into the semester, Group Two was evaluated to be much more active than it was in previous weeks, therefore it was reasonable to evaluate all of the weeks individually. The resulting data also suggests that Group Two was more stable as its averages per week had less variation. This is not visualized in any of the figures.

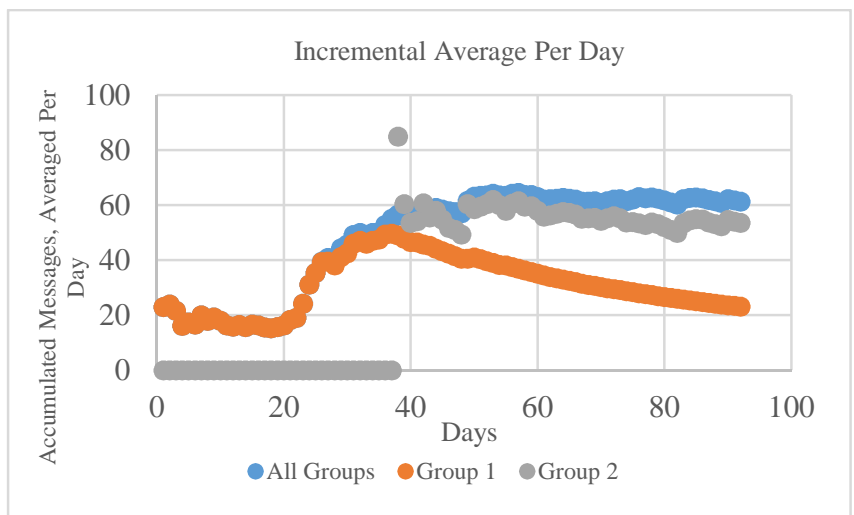

Fig. 5. Group Two exhibited constant activity on average while Group One exhibited shock then attrition behavior.

Group One originally experienced attrition and a shock growth. Then, Group Two emerged and had consistent participation. For context, the members of Group One never spoke again around day fifty, causing the downward parabolic curve.

Another metric used was accumulated average posts on the WhatsApp groups, per day-visualized in Figure 5. The evaluated average of messages was contributed per day, and as those days increased (i.e. if the first day had twenty messages, the average per day for the first day was twenty messages). However, if on the second day only ten messages came in, then the average per day for the second day was fifteen messages. This is a significant technique of analysis because it demonstrates that Group Two had consistent participation on average per day.

Notably, the second group experienced attrition as well. However, this result is debatable due to a calculated R-squared value that was below 0.5 .

\section{1 st Attempt Grades}

The data shows that mere participation in Group Two contributed to a statistically significant increase in grades per individual, which contradicts the initial hypothesis, namely that study group formation works to benefit the performance of each individual member. Moreover, the data shows that the number of subsequent quiz attempts increases for all of Group Two by a statistically significant margin when compared to the rest of the class, which suggests that being in a group can be somewhat detrimental to one's performance over time, albeit not significantly harmful to the overall outcome. With the lack of an observable trend in grade difference over time, and taking into account the fact that each group member did achieve an objectively high final grade, these trends suggest that the members who formed the groups had the propensity to perform well regardless of their active participation in the groups.

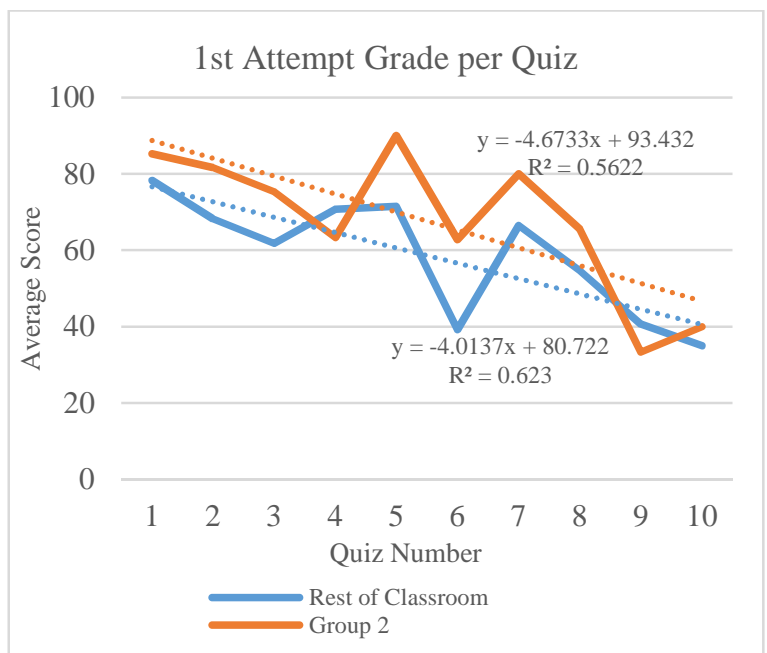

Fig. 6. Group Two students maintained a consistent lead over other students in the class.

\section{Overall Grades}

The grading system of the course's lab assignments was designed such that a fully working lab would receive full marks, and any submissions that did not function would receive few points, if any at all. With such a system, the propensity to receive an incomplete or "near-perfect" grade was lowered, which worked beneficially for Group Two to achieve high marks, and possibly to form in the first place.

Each and every member of the group approached the laboratory assignments with utmost dedication as individuals, but ultimately could not surmount some of the assignments on their own, and as such formed the group. After group formation, this dedication was perpetuated, causing the members of Group Two to have a higher grade per assessment than the class on average.

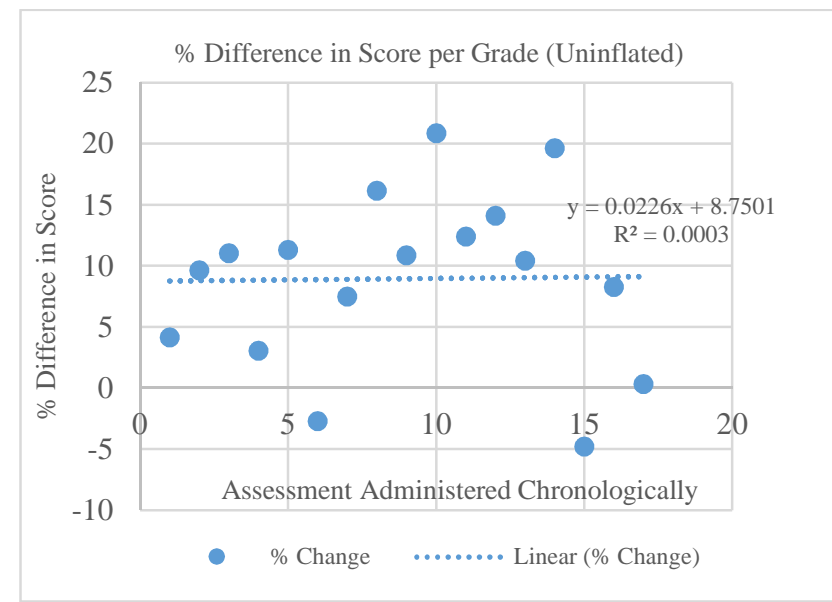

Fig. 7. \% Difference between Group Two and the rest of the class did not widen.

$14^{\text {th }}$ LACCEI International Multi-Conference for Engineering, Education, and Technology: "Engineering Innovations for Global Sustainability”, 20-22 July 2016, San José, Costa Rica. 
6. Content of Conversations: Academic vs. Social vs. Comradery

Group Two's conversation was analyzed line by line and tallied for posts that were deemed Academic, Social, or Comradery and the results are visualized in Figure 8. Messages were deemed "Academic" in nature if they reflected any of this non-exhaustive list of criteria: questions about a concept in Logic Design, deadlines for assignments, answers to Logic Design questions, comment on the class or university, and other topics of an academic nature. Messages were deemed "Social" in nature if they reflected any of this non-exhaustive list of criteria: meeting up for dinner, planning a party, inviting someone new to the group, and other topics of a social nature. Messages were deemed "Comradery" in nature if they reflected any of this non-exhaustive list of criteria: jokes, memes, pranks, and other topics regarding morale.

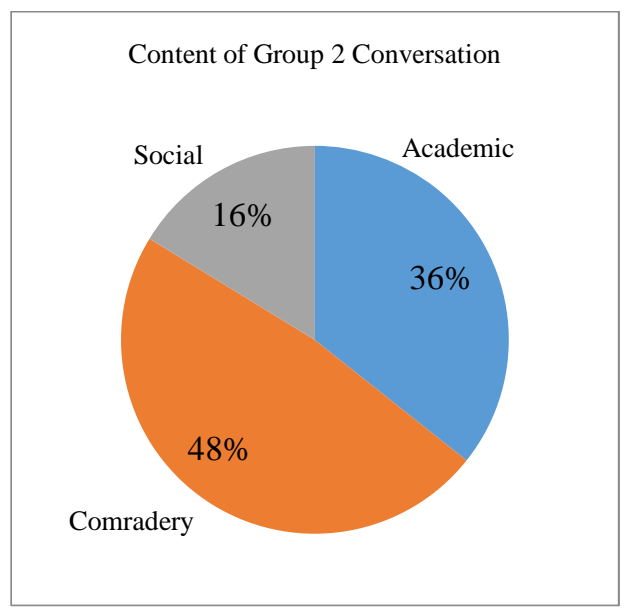

Fig. 8. Content of Group Two's total conversation was predominantly Comradery in nature.

\section{Outcomes}

\section{Group Schism was caused by Individual Interests}

Ultimately we found that success as individuals in Intro to Logic Design would come as a result of being members of a group. The formation of the first group, experimentally referred to as "Group One" was rapid and unregulated. Even though common sense would suggest that more members in the group would be a good thing, the core students who would go on to form "Group Two" found that the group was becoming prohibitively large. It appeared as though the zeitgeist had shifted and some members of the group noticed that others were simply not participating as much as they had. This led to fears of being socially obligated to cater to free-riders.

The second group was formed to remove this sense of unease and thusly splintered off from the original group by tacitly deciding not to invite the "free-riders" into the reincarnate group. This group remained strong and did not splinter into any other groups because the individuals felt satisfied. They suggested that the goals of the group were clear, the group size was preferable, and it was still made up of students who wanted to succeed in the course.

Group formation is simple, but the group needs to be sufficiently homogeneously composed of individuals in order to survive. In other words, Group Two survived because the group was made up of similar individuals. Repeating such a feat with random members is likely to cause ineffective groups.

\section{Group Participation Motivates Individuals to Succeed as Individuals}

For each of the students in Group Two, Introduction to Logic Design was the highest or one of the highest grades for the entire semester as shown in Figure 3. Every student was an engineering student either in Computer Science, Computer Engineering, Electrical Engineering, or Ocean Engineering, taking classes like Differential Equations, Calculus II, Circuits I, Electronics I, etc. Introduction to Logic Design is similar in rigor to these classes comparatively, making these results more significant for students in the future. Being in a group for Logic Design could very well have resulted in each individual achieving a high grade for themselves. For students who have a negative outlook on group participation, feel intimidated by working with others, or simply prefer to work on their own to accomplish tasks, it is well-intentioned advice to consider not only participating in a group, but to also form one.

\section{Group Participation Does Not Demonstrably Influence Grades for that Class}

Before embarking on the data gathering process, many members of the team assumed that the group's performance relative to the rest of the class would widen. This belief turned out to be unsubstantiated by data, and that had the group not been present at all, our individual performances aggregately compared to the class average would've yielded exactly the same results.

However, while being in a group or not seems to have no impact on our individual grades compared to the rest of the students in our Introduction to Logic Design class, being in a group in Introduction to Logic caused us to individually perform better in that class relative to the rest of our classes.

This seems to indicate that while group participation doesn't automatically make an individual a better student relative to an individual who stakes the class alone, being in a group does make an individual perform better in that class where he/she is involved in a group.

\section{Gender and Minority Groups}

Conventional research on the topic of how gender and minorities play into group dynamics generally indicated that team dynamics are damaged when minorities and women compose less than $15 \%$ of the total group [8]. An understandable extension of these results could be that increasing the composition of minorities and women in groups would lead to positive group dynamics. However, later research countered this hypothesis noting that the threat of being stereotyped escalates, causing the group to splinter anyway [9]. On the subject of gender composition and group dynamics, an MIT study asserted that the key to strong group dynamic is a group composed of socially sensitive members [3]. Ultimately, group members who were interviewed in studies found that 
more often than not, they were recognized not for their race or gender, but rather their academic merit [10].

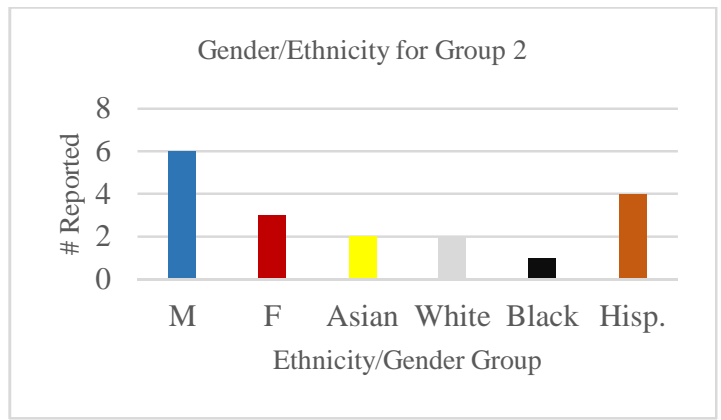

Figure 9. Group Two had an ethnically balanced composition.

Group Two did not find these effects present in the group dynamic. This is only a hypothesis — but it could be said that the effects were not present in our group because the group was predominantly ethnic as shown in Figure 9. Similar to the findings of the MIT study, perhaps females and ethnic individuals are more socially sensitive to the power struggle of taking turns in the middle of a group. A further investigation should attempt to isolate independent variables such as ethnicity and specifically enumerate what qualifies as group dynamics.

\section{Successful Group Attributes}

It is our assertion that successful groups are composed of successful individuals, have a high ratio of females to males, a ratio of ethnic to white people that exceeds $2: 1$, and that the group be composed of sufficiently like-minded individuals. Furthermore, we assert that successful groups must be formed in the proper environment. Professors must suggest that the group form in the first place, and must offer multiple grade opportunities per grade such that individuals have multiple attempts to get the highest grade possible.

\section{CONCLUSION AND FUTURE WORK}

In conclusion, social networking is effective for improving individual academic performance. It was beneficial to conduct this research because social networking as a tool in academics is an untapped field of exploration. In our technologically advancing society, online collaboration is becoming increasingly common even though it is not nearly as well understood. Furthermore, to better address the issue of increasing rates of engineering undergraduate student drop-outs in the US, we as researchers must analyze successful methods performed by students in similar majors taking challenging courses. By tracking this group's activity and outcome as a whole based on a myriad of parameters, predicted trends were able to be verified, although it is reasonable to assume that the pool of collected data was too small to make a statistically generalizable conclusion.

In future work, a similar study would be modeled after this one in other core courses that span a variety of engineering disciplines with a greater amount of participants and a more pointed control group. Future studies would allow group formation to be left "up to the students" as this study's was, although the key difference would be restrictions on how many people would be required per group in order to verify that smaller groups do indeed have a strong effect on the evolution cycle of a collaborative group. It would also be of interest to analyze whether the diversity that was so prevalent in WhatsApp Group Two would also occur naturally for other groups formed under similar conditions.

\section{ACKNOWLEDGMENT}

We would like to acknowledge Dr. Maria Larrondo Petrie for her suggesting our group to conduct this research. We would like to thank the Florida Atlantic University (FAU) College of Engineering and Computer Science for building Engineering East and the student study space, called "The Cube", where many hours and ounces of sweat and tears were poured out. Finally, we thank the FAU Student Government Association and the Department of Computer and Electrical Engineering and Computer Science for helping fund our travel to present this paper.

\section{REFERENCES}

[1] Matthews, M. (2012, August 27). "Keeping students in engineering: A research-to-practice brief: American Society for Engineering Education." [https://www.asee.org/retention-project]

[2] Pang, Y., Mugno, R., \& Xue, X. (2015). Diversity and anxiety: A case study on collaborative testing. 2015 IEEE

[3]Driskell, J. E., Salas, E., \& Hughes, S. (2010). Collective orientation and team performance: Development of an individual differences measure. Human Factors, 52, 316-328. http://dx.doi.org/10 .1177/0018720809359522

[4] Margolis, S. (2011). What is the optimal group size for decision-making? Sheila Margolis. Retrieved January 31, 2016, from http://sheilamargolis.com/2011/01/24/what-is-the-optimal-group-size-fordecision-making/

[5] Toseland, R. W., \& Rivas, R. F. (1984). An introduction to group work practice (Pg.67). New York: Macmillan.

[6] Shih, P. C., Nguyen, D. H., Hirano, S. H., Redmiles, D. F., \& Hayes, G. R. (2009). GroupMind. Proceedings of the ACM 2009 International Conference on Supporting Group Work - GROUP '09(pg.72).

[7] Beal, G. M., Bohlen, J. M., \& Raudabaugh, J. N. (1962). Leadership and dynamic group action. Ames: Iowa State University Press.

[8]McDermott, F. (2002). Inside Group Work. Crows Nest, NSW: Allen \& Unwin.

[9]Sabin, S. I., \& Pomohaci, M. (2014). GROUP COHESION IMPORTANT FACTOR IN SPORT PERFORMANCE. European Scientific Journal, 10(26) Retrieved from

http://ezproxy.fau.edu/login?url=http://search.proquest.com/docview/1652469 581 ? accountid $=10902$

[10] Kanter, E.M., 1977. Some effects of proportions on group life: skewed sex ratios and responses in token women. Am. J. Sociol., 82:965-990.

[11] Haag, S.G., 2000. Teaming Backlash: Reframing Female Engineering Students. Proceed. 2000 ASEE Conf.

Frontiers in Education Conference (FIE).

[12] Woolley, A. W., Chabris, C. F., Pentland, A., Hashmi, N., \& Malone, T. W. (2010). Evidence for a Collective Intelligence Factor in the Performance of Human Groups. Science, 330(6004), 686-688.

[13] The Foundation Coalition. (2002, March 01). Forming Student Engineering Teams. Retrieved January 29, 2016, from http://www.foundationcoalition.org/publications/brochures/2002-Mar01_Forming_Teams.pdf

14 ${ }^{\text {th }}$ LACCEI International Multi-Conference for Engineering, Education, and Technology: "Engineering Innovations for Global Sustainability", 20-22 July 2016, San José, Costa Rica. 


\section{APPENDIX A}

PHP Code for Manipulating WhatsApp Conversations

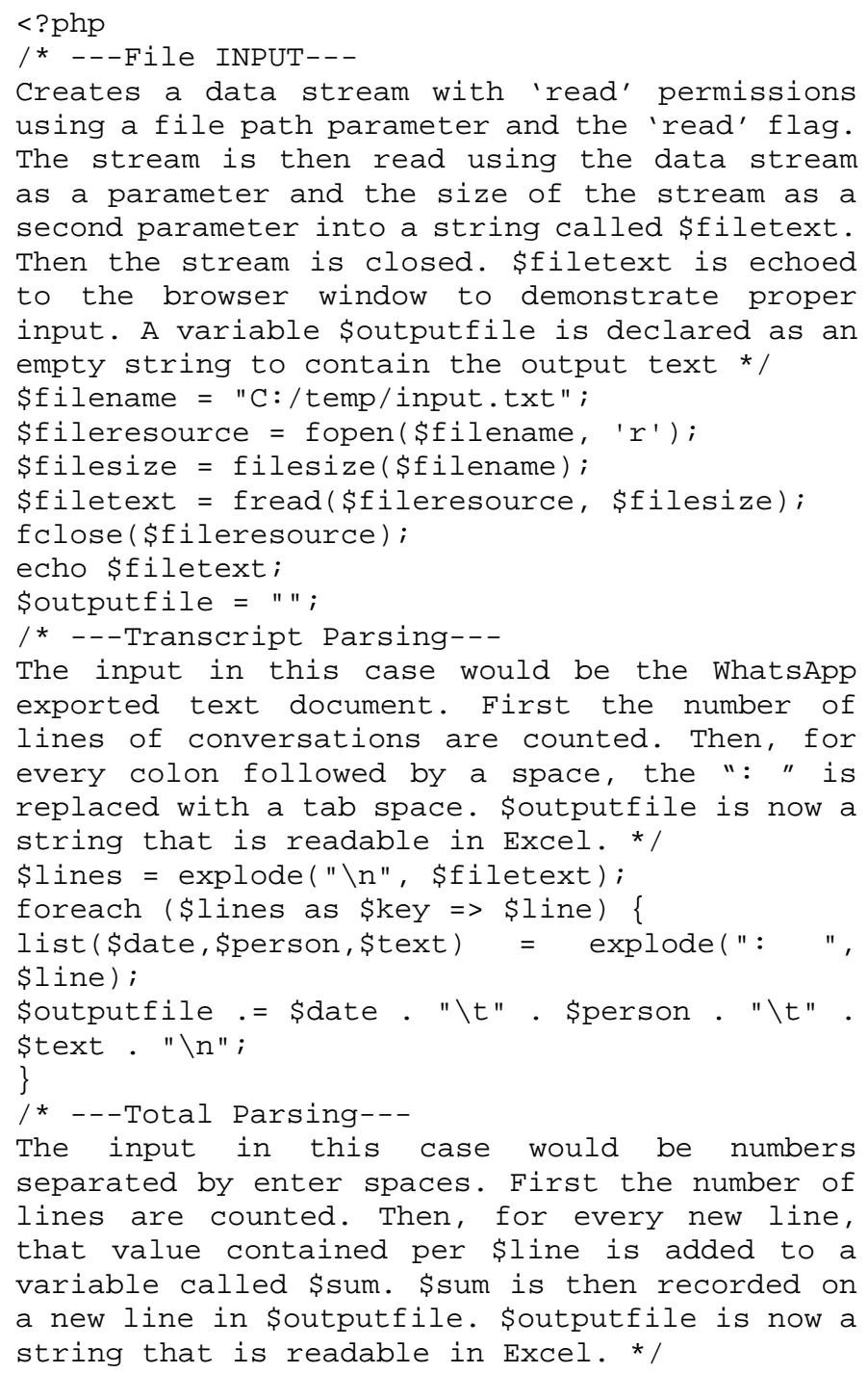

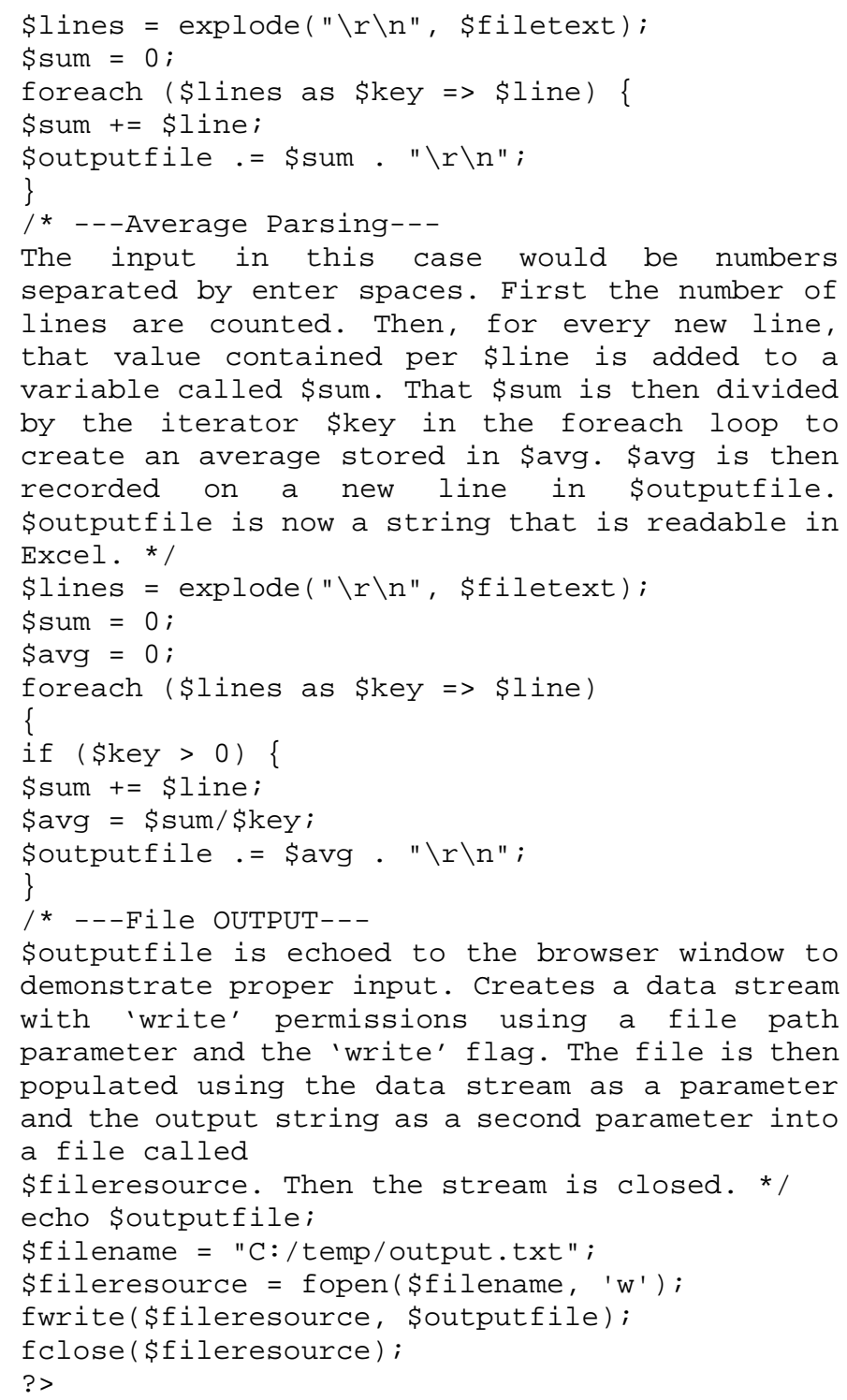

$14^{\text {th }}$ LACCEI International Multi-Conference for Engineering, Education, and Technology: "Engineering Innovations for Global Sustainability”, 20-22 July 2016, San José, Costa Rica. 